\title{
Determination of Postprandial Glycemic Responses by Continuous Glucose Monitoring in a Real-World Setting
}

\author{
Martin Röhling ${ }^{1, *}++^{+}$, Tobias Martin ${ }^{2,+}$, Meinolf Wonnemann ${ }^{3}$, Martin Kragl ${ }^{3}$, \\ Horst Harald Klein ${ }^{2}$, Lutz Heinemann ${ }^{4}$, Stephan Martin ${ }^{1,5}$ and Kerstin Kempf ${ }^{1}$ (D) \\ 1 West-German Centre of Diabetes and Health, Düsseldorf Catholic Hospital Group, Hohensandweg 37, \\ 40591 Düsseldorf, Germany; Stephan.Martin@uni-duesseldorf.de (S.M.); kerstin.kempf@wdgz.de (K.K.) \\ 2 Faculty of Medicine, Ruhr-University Bochum, 44801 Bochum, Germany; \\ tobias.martin130297@gmail.com (T.M.); harald.klein@bergmannsheil.de (H.H.K.) \\ 3 Bionorica SE, 92318 Neumarkt, Germany; meinolf.wonnemann@bionorica.de (M.W.); \\ martin.kragl@bionorica.de (M.K.) \\ 4 Science Consulting in Diabetes GmbH, 41462 Neuss, Germany; lutz.heinemann@profil.com \\ 5 Faculty of Medicine, Heinrich Heine University Düsseldorf, 40225 Düsseldorf, Germany \\ * Correspondence: martin.roehling@vkkd-kliniken.de; Tel.: +49-(0)211-56-60-360-66; \\ Fax: +49-(0)211-56-60-360-72 \\ + The authors equally contributed to this work.
}

Received: 31 July 2019; Accepted: 27 September 2019; Published: 27 September 2019

check for updates

\begin{abstract}
Background: Self-monitoring of blood glucose using capillary glucose testing $(\mathrm{C})$ has a number of shortcomings compared to continuous glucose monitoring (CGM). We aimed to compare these two methods and used blood glucose measurements in venous blood (IV) as a reference. Postprandial blood glucose levels were measured after $50 \mathrm{~g}$ oral glucose load and after the consumption of a portion of different foods containing $50 \mathrm{~g}$ of carbohydrates. We also evaluated the associations between postprandial glucose responses and the clinical characteristics of the participants at the beginning of the study. Methods: 12 healthy volunteers (age: $36 \pm 17$ years, BMI: $24.9 \pm 3.5 \mathrm{~kg} / \mathrm{m}^{2}$ ) ate white bread (WB) and whole grain (WG) bread and drank a $50 \mathrm{~g}$ glucose drink as reference. Postprandial glucose responses were evaluated by CGM, IV and C blood glucose measurements. Incremental area under the curve $\left(\mathrm{AUC}_{\mathrm{i}}\right)$ of postprandial blood glucose was calculated for $1 \mathrm{~h}\left(\mathrm{AUC}_{\mathrm{i} 0-60}\right)$ and $2 \mathrm{~h}$ $\left(\mathrm{AUC}_{\mathrm{i} 0-120}\right)$. Results: After the consumption of white bread and whole grain bread, the $\mathrm{AUC}_{\mathrm{i}} 0-60 \mathrm{~min}$ did not differ between CGM and IV or C. AUC $\mathrm{A}_{\mathrm{i}-120 \mathrm{~min}}$ of CGM showed no difference compared to C. Correlation analyses revealed a positive association of age with glucose $\mathrm{AUC}_{\mathrm{i} 0-120}(r=0.768 ; P=0.004)$ and WG AUC $\mathrm{i}_{0-120}(r=0.758 ; P=0.004)$; fasting blood glucose correlated with WG AUC $\mathrm{A}_{0-120}(r=0.838$; $P<0.001)$. Conclusion: Despite considerable inter-individual variability of postprandial glycemic responses, CGM evaluated postprandial glycemic excursions which had comparable results compared to standard blood glucose measurements under real-life conditions. Associations of $\mathrm{AUC}_{\mathrm{i} 0-60}$ and $\mathrm{AUC}_{\mathrm{i} \text { 0-120 }}$ postprandial glucose response with age or fasting blood glucose could be shown.
\end{abstract}

Keywords: postprandial glucose response; continuous glucose monitoring

\section{Introduction}

Self-monitoring of blood glucose (SMBG) levels in capillary blood samples is still the most widely-used method for the evaluation of glucose control in patients with glucometabolic diseases [1]. Blood glucose measurement evaluates foods according to their impact on postprandial glycemic excursions [2]. It is of interest to note that the postprandial response to a definite foodstuff shows a high 
inter- and intra-individual variability [3]. Parts of this variability are also be caused by methodological issues [4]. However, despite its importance, particularly when considering increasing prevalence rates of impaired glucose tolerance and diabetes [5], no method exists for determining and predicting an individual postprandial blood glucose response to food [6]. Compared to standard measurement methods, such as capillary or venous blood glucose testing, continuous glucose monitoring (CGM) might be able to conduct a more comprehensive glycemic assessment and overcomes some of the shortcomings of the other methods [7]. This advantage could allow an individual and comprehensive evaluation of daily glycemic excursions.

The aim of the present study was (i) to examine whether CGM allows for the appropriate evaluation of postprandial blood glucose levels under real-life conditions and to (ii) investigate the association between different parameters of glycemic responses with descriptive parameters of the study subjects.

\section{Materials and Methods}

\subsection{Study Population}

Twelve healthy eligible male volunteers (inclusion criteria: $\geq 18$ years old; exclusion criteria: acute diseases, severe illness with in-patient treatment during the last 3 months, weight change $>2 \mathrm{~kg} /$ week during the last month, smoking cessation during the last 3 months, drugs for active weight reduction, chronic medication, fasting blood glucose $>125 \mathrm{mg} / \mathrm{dL}$ (diabetes)) were included. The first participant was enrolled on 1 Dec 2018 and the last participant finished the study on 31 May 2019. The study was conducted at the West-German Centre of Diabetes and Health (WDGZ) in Düsseldorf, Germany, in accordance with the ethical standards laid down in the 1964 Declaration of Helsinki and its later amendments. The research protocol was approved by the ethics committee of the "Ärztekammer Nordrhein", Düsseldorf (No. 2017409). All participants gave written informed consent prior to their inclusion into the study.

\subsection{Foodstuff}

Two products were studied: white bread (Butter Toast ${ }^{\circledR}$, Golden Toast, Wittenberg, Germany) and whole grain bread (1688 Mehrkorn ${ }^{\circledR}$, Harry-Brot, Schenefeld, Germany). One portion (containing $50 \mathrm{~g}$ digestible carbohydrates) was eaten immediately before the beginning of the test in the morning after an overnight fast of at least $10 \mathrm{~h}$. Before testing, participants ate as usual on the previous day without a standard meal and refrained from consuming alcohol and exercising for $72 \mathrm{~h}$. A 200-mL glucose drink (Accu-Chek Dextrose O.G.-T. Saft ${ }^{\circledR}$, Roche Diabetes Care, Mannheim, Germany), containing also $50 \mathrm{~g}$ of carbohydrates, was used as the reference product. Energy and macronutrient distribution of foods are shown in Table S1.

\subsection{Study Design}

One day prior to the study beginning, participants were equipped with a CGM system (FreeStyle Libre $^{\circledR}$, Abbott Diabetes Care, Alameda, CA, USA), i.e., the glucose sensor of this system was attached to the upper arm. This CGM system provides glucose recordings every 15 min over a period of 14 days. The glucose data were downloaded manually by a scan with a handheld device. The sensor accuracy of 73.2\% had been determined using ISO 15197:2013 (= percentage of sensor values that are within $0.8 \mathrm{mmol} / \mathrm{L}$ of the reference value at glucose concentrations $<5.6 \mathrm{mmol} / \mathrm{L}$ and within $15 \%$ at glucose concentrations $\geq 5.6 \mathrm{mmol} / \mathrm{L}$ ) [8]. The mean absolute relative difference (MARD) between sensor and venous glucose measurements was $13.2 \pm 10.9 \%$ [8]. Other methods of determination for the accuracy of CGM confirm strong correlations $\left(r^{2}=0.90\right)$ with venous blood glucose levels [9] as well as capillary blood glucose levels [10].

On the second day of the study, participants consumed portions of these three test products containing $50 \mathrm{~g}$ of available carbohydrate on 3 separate days without a washout period. The products 
were tested in random order at the same time of the morning after a $10 \mathrm{~h}$ overnight fast. Venous blood samples (IV) were collected at 0, 15, 30, 45, 60, 75, 90, 105 and $120 \mathrm{~min}$ postprandial by inserting an intravenous cannula into a forearm vein. Capillary blood samples $(C)$ were obtained through finger pricking. Blood glucose levels in these samples were measured with a high quality SMBG system (ContourXT/Contour next, Ascensia Diabetes Care, Leverkusen, Deutschland, Germany).

\subsection{Measurements}

Participants visited the WDGZ at the first day of the study for determination of anthropometric measurements and clinical data comprising age, body weight, height, body mass index (BMI), waist circumference and fat mass. Blood samples for measurement of total cholesterol, high-density lipoprotein (HDL) cholesterol, low-density lipoprotein (LDL) cholesterol, triglycerides, hemoglobin $\mathrm{A} 1 \mathrm{c}(\mathrm{HbA1c})$, fasting blood glucose, and fasting plasma insulin were taken as well. Body weight was measured in light clothing to the closest $0.1 \mathrm{~kg}$, height to the closest $0.5 \mathrm{~cm}$, and waist circumferences at the minimum abdominal girth (midway between the rib cage and the iliac crest). Fat mass (FM) was determined by bioelectrical impedance analysis with multi frequency measuring using a body composition scale (Seca mBCA515, Seca, Hamburg, Germany). Venous blood samples were collected for the determination of laboratory parameters and were analyzed at the local laboratory with intra-assay coefficients of variability (CV) of 1.6\% for $\mathrm{HbA} 1 \mathrm{c}, 1.9 \%$ for fasting blood glucose, $3.6 \%$ for insulin, $2.8 \%$ for HDL cholesterol, 3.3\% for LDL cholesterol, $2.6 \%$ for total cholesterol, and 2.9\% for triglycerides [11]. To protect venous blood samples from hemolysis, S-Monovette ${ }^{\circledR}$ tubes (SARSTEDT, Nümbrecht, Germany) were used [12].

\subsection{Calculation of Glycemic Variables}

The incremental AUC $\left(\mathrm{AUC}_{\mathrm{i}}\right)$ of postprandial glucose excursions was calculated geometrically as the sum of the areas of the triangles and trapezoids over $2 \mathrm{~h}$, excluding the area below the initial fasting glucose concentration [13].

\subsection{Statistical Analysis}

Data are presented as arithmetic means and standard deviations (mean $\pm \mathrm{SD}$ ). Moreover, data which were not normally distributed were analyzed with Mann-Whitney $U$ or Wilcoxon and Spearman rank correlation test to determine differences between measurement procedures and to determine correlations between variables. Postprandial blood glucose excursions of a glucose drink, white bread and whole grain bread were analyzed after 60 and $120 \mathrm{~min}$.

Multiple linear regression analyses were performed in which $\mathrm{AUC}_{\mathrm{i}}$ had been set as a dependent variable and age, $\mathrm{BMI}$, fasting blood glucose, $\mathrm{HbA1c}$, and fasting plasma insulin levels as independent variables. All statistical tests were two sided, and the level of significance was set at $\alpha=0.05$. All analyses were performed using SPSS 22.0 (SPSS Inc., Chicago, IL, USA) and GraphPad Prism 6.04 (GraphPad Software, San Diego, CA, USA).

\section{Results}

Study population. All participants finished the study (Table 1, Figure 1) and no adverse effects were reported.

Fasting glucose levels and postprandial glycemic excursions. Fasting blood glucose values at $\mathrm{t}=0$ min differed significantly between the three glucose measurements (IV: $91 \pm 10 \mathrm{mg} / \mathrm{dL} ; \mathrm{C}: 98 \pm 9 \mathrm{mg} / \mathrm{dL}$; CGM: $84 \pm 12 \mathrm{mg} / \mathrm{dL}$; all $P<0.001$ ). Postprandial glucose excursions in the first $60 \mathrm{~min}$ after drinking the glucose drink $\left(A U C_{i} 0-60 \mathrm{~min}\right)$ as well as in the first $120 \mathrm{~min}\left(\mathrm{AUC}_{\mathrm{i} 0-120 \mathrm{~min}}\right)$ were significantly higher in $C$ and CGM compared to IV (all $P<0.01$ ). After the consumption of white bread and whole grain bread the AUC $\mathrm{A}_{\mathrm{i}-60 \mathrm{~min}}$ did not differ between CGM and IV but between $\mathrm{C}$ and IV $(P<0.01)$. However, $\mathrm{AUC}_{\mathrm{i}}$ 0-120min was significantly higher in C and CGM vs. IV (both $P<0.01$, Figure 2a-c). Absolute postprandial glucose changes are shown in Figure 2d-f. 
Table 1. Baseline characteristics.

\begin{tabular}{cc}
\hline & Study Group $(\boldsymbol{n}=\mathbf{1 2})$ \\
\hline Age $($ years $)$ & $36 \pm 17$ \\
\hline Weight $(\mathrm{kg})$ & $84 \pm 12$ \\
\hline BMI $\left(\mathrm{kg} / \mathrm{m}^{2}\right)$ & $24.9 \pm 3.5$ \\
\hline Waist circumference $(\mathrm{cm})$ & $89 \pm 12$ \\
\hline Fat mass $(\%)$ & $26 \pm 6$ \\
\hline Fat mass $(\mathrm{kg})$ & $20 \pm 8$ \\
\hline HbA $1 \mathrm{c}(\%)(\mathrm{mmol} / \mathrm{mol})$ & $5.3 \pm 0.5(34.1 \pm 5.4)$ \\
\hline Fasting blood glucose $(\mathrm{mg} / \mathrm{dL})(\mathrm{mmol} / \mathrm{L})$ & $1.7 \pm 0.1$ \\
\hline Fasting plasma insulin $(\mathrm{uU} / \mathrm{mL})(\mathrm{pmol} / \mathrm{L})$ & $7.5 \pm 4.0(54.1 \pm 28.4)$ \\
\hline HOMA-IR & $165 \pm 36(4.3 \pm 0.9)$ \\
\hline Total cholesterol $(\mathrm{mg} / \mathrm{dL})(\mathrm{mmol} / \mathrm{L})$ & $53 \pm 13(1.4 \pm 0.3)$ \\
\hline HDL $(\mathrm{mg} / \mathrm{dL})(\mathrm{mmol} / \mathrm{L})$ & $105 \pm 38(2.7 \pm 1.0)$ \\
\hline LDL $(\mathrm{mg} / \mathrm{dL})(\mathrm{mmol} / \mathrm{L})$ & $119 \pm 62(1.3 \pm 0.7)$ \\
\hline Triglyceride $(\mathrm{mg} / \mathrm{dL})(\mathrm{mmol} / \mathrm{L})$ &
\end{tabular}

Shown are means \pm standard deviations; $\mathrm{BMI}$, body mass index; $\mathrm{HbA}_{1 \mathrm{c}}$, glycated hemoglobin $\mathrm{A}$; $\mathrm{HDL}$, high-density-lipoprotein; HOMA-IR, homeostatic model assessment-insulin resistance; LDL, low-density-lipoprotein.

Correlation analyses: Age was positively correlated with the $\mathrm{AUC}_{\mathrm{i} 0-60}(r=0.629 ; P=0.029)$ and AUC $_{\mathrm{i} 0-120}(r=0.768 ; P=0.004)$ after the glucose drink (Table S2). This correlation also existed for whole grain bread $\left(\mathrm{AUC}_{\mathrm{i} 0-60}: r=0.867 ; P<0.001 ; \mathrm{AUC}_{\mathrm{i} 0-120}: r=0.758 ; P=0.004\right)$. Fasting blood glucose correlated positively with $\mathrm{AUC}_{\mathrm{i} 0-120}$ after the glucose drink $(r=0.620 ; P=0.032)$, whole grain bread $\mathrm{AUC}_{\mathrm{i} 0-60}(r=0.838 ; P<0.001)$ and whole grain bread $\mathrm{AUC}_{\mathrm{i} 0-120}(r=0.838 ; P<0.001)$.

\section{CONSORT}

TRANSPARENT REPORTING of TRIALS

CONSORT 2010 Flow Diagram

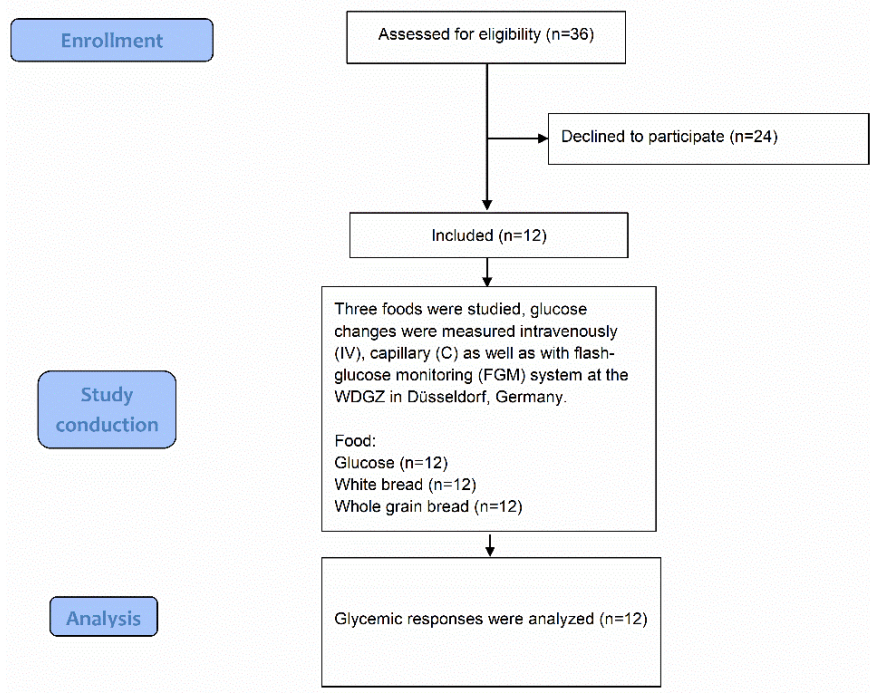

Figure 1. Consort flow diagram. 

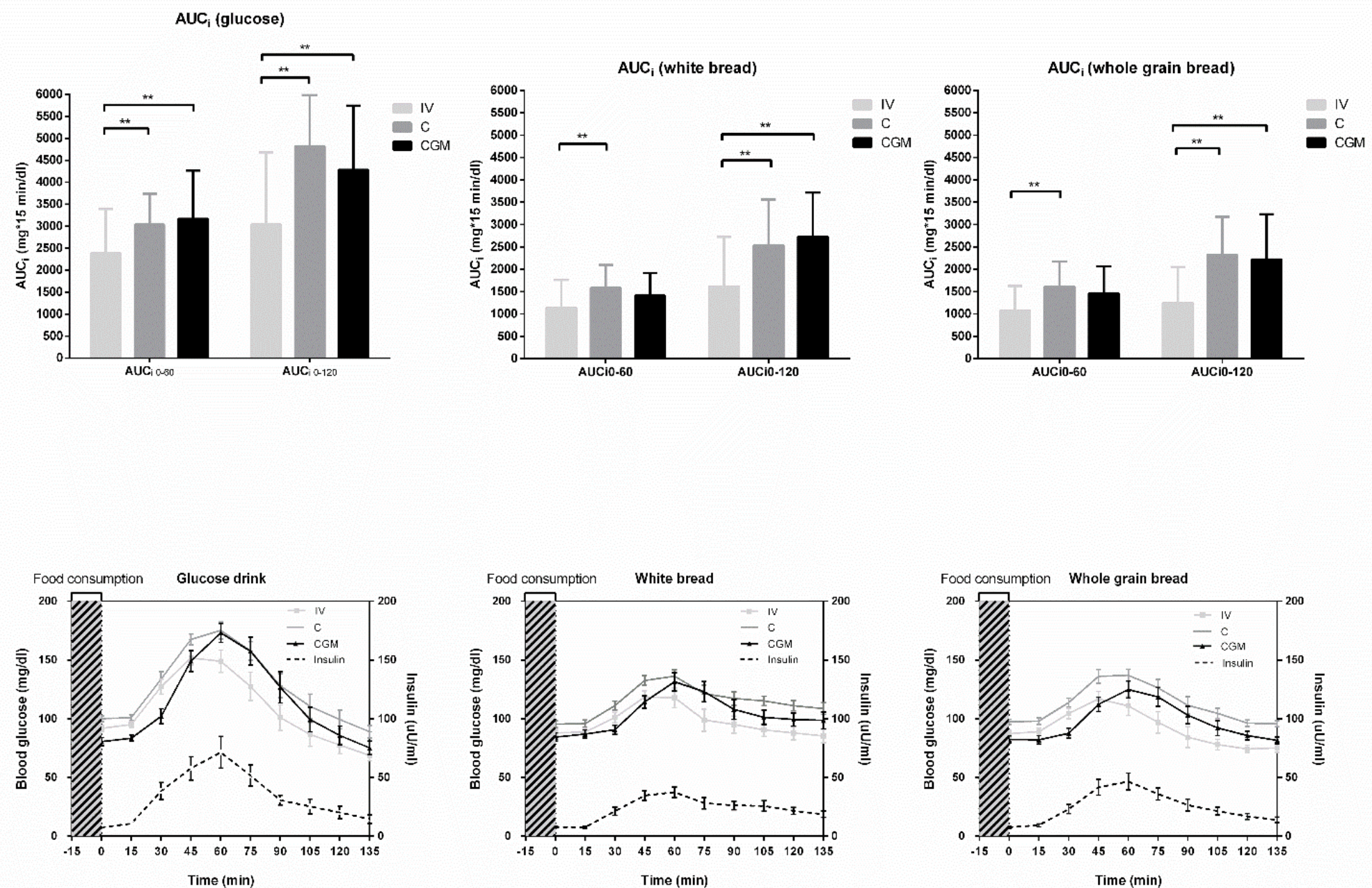

Figure 2. Postprandial glucose responses as $A U C_{i} 0-60$ and $A U C_{i}$ 0-120 after (a) glucose, (b) white bread or (c) whole grain bread consumption and as absolute values after (d) glucose, (e) white bread, and (f) whole grain bread consumption. IV, intravenously; C, capillary; CGM, continuous glucose monitoring. Shown are means \pm $\mathrm{SD} ;{ }^{* *} P<0.01$. 


\section{Discussion}

The usage of a CGM system for the evaluation of postprandial glycemic excursions in a real-world-setting resulted in comparable results as opposed to using the standard blood glucose measurement capillary glucose testing. Since CGM provides more data than serial blood glucose measurements, it allows for a more comprehensive glycemic assessment (i.e., the most notable benefit of CGM is the wealth of time-series glucose data revealing real-time temporal trends and patterns and the ability to announce if glucose levels are detected above or below a specific threshold) [14]. Furthermore, CGM overcomes some drawbacks of blood glucose measurements (e.g., user error on test accuracy, the need for multiple fingerstick blood samples each day, and the limited data available (only a single snap shot of glucose concentrations and not trending data) $[14,15])$, and has been evaluated in patients without [16] and with type 1 or type 2 diabetes $[7,17]$.

As food items with fast absorbable carbohydrates induce a rapid increase in postprandial glucose excursions, $\mathrm{AUC}_{\mathrm{i}}$ was calculated for the $1^{\text {st }}$ hour and $2 \mathrm{~h}$ after starting eating. There were significant correlations of $\mathrm{AUC}_{\mathrm{i}}$ in the first $60 \mathrm{~min}$ with the glucose drink and whole grain bread as well as a strong correlation of $\mathrm{AUC}_{\mathrm{i}}$ in the $120 \mathrm{~min}$ with whole grain bread with the independent variables age and fasting blood glucose. Earlier studies have shown that particularly age [18] as well as sex are strong influencing factors. Furthermore, fasting blood glucose correlated with the $1 \mathrm{~h}$ and $2 \mathrm{~h}$ values of postprandial blood glucose response. Further factors that may affect postprandial glucose responses comprise genetics [19], lifestyle [20], exocrine pancreatic and glucose transporters activity levels [21], as well as gut microbiota [6].

Certain strengths and limitations of our study have to be considered. Only men were included in the study to avoid gender-specific influences, especially with regard to the strong impact of the menstrual cycle and oral contraceptives on postprandial glucose excursions [22] or differences in glucose clearance between males and females and potential deviations in fat oxidation. Therefore, the findings might not be generalizable or transferable to other cohorts, particularly with metabolic impairments like diabetes. However, the real-life study approach indicates that CGM could be a pragmatic alternative for individual everyday usage to determine postprandial glucose changes. A further limitation could be the low sample size $(n=12)$. The lack of power might have led to no differences among methods. In future studies, more complex analyses methods could be used to analyze longitudinal data in more detail, applying mixed effect models considering complex correlation structures, irregularly spaced visits, missing data, and mixtures of time-varying and static covariate effects. There are also differences in fasting blood glucose levels between the measurements. This difference is probably caused by the different fluids (venous, capillary and subcutaneous) taken from different compartments during blood sampling [9].

The major strength of this study is the innovative approach to determine individual glycemic responses for common carbohydrate-containing foods based on a CGM system. As postprandial glycemic response has strong inter-subject variability, our approach makes it possible that every person can determine their individual glycemic responses by using CGM systems, which could be an important step for the management of blood glucose levels. Although CGM systems were primarily developed for patients with diabetes, the present findings indicate potential benefits and application possibilities, even for healthy people, for educative purposes to adapt eating and moving habits, aiming to keep blood glucose levels within a normal range. Moreover, real-time information regarding glucose can be useful in the case of nutrition-related uncertainties. Furthermore, CGM curves could also be used in future studies to determine individual glycemic indices, especially when considering the inter-individual variability of postprandial glucose responses [6].

The present study points towards a useful application of CGM systems for the determination of individual postprandial glycemic responses under everyday life conditions.

Supplementary Materials: The following are available online at http://www.mdpi.com/2072-6643/11/10/2305/s1, Table S1: Energy and macronutrient distribution of foods, Table S2: Correlation matrix between $\mathrm{AUC}_{\mathrm{i}}$ and selected patient and baseline characteristics. 
Author Contributions: M.R. researched and collected data, performed the statistical analysis, and wrote the manuscript. T.M. researched and collected data. M.W., M.K. and S.M. had the idea, initiated the study and revised the manuscript. K.K., H.H.K., and L.H. contributed to the study design and revised the manuscript. S.M. and K.K are the guarantors of this work and, as such, had full access to all the data in the study and take responsibility for the integrity of the data and the accuracy of the data analysis.

Funding: The study was financially supported by Bionorica SE. The funder had no influence on study design, data collection, data analysis, manuscript preparation and/or publication decisions.

Acknowledgments: We thank our study nurse Bettina Prete (West-German Centre of Diabetes and Health) for her excellent work.

Conflicts of Interest: M.R., T.M., H.H.K. and K.K. declare that there are no competing interests regarding this publication. S.M. received research support from Bionorica SE for conducting the current study. M.W. and M.K. are scientific employees of Bionorica SE., L.H. is a consultant for a number of companies that develop novel diagnostic and therapeutic options for diabetes treatment; e.g., Roche Diabetes Care, Becton Dickinson, Lifecare, Berlin-Chemie. LH is shareholder of the Profil Institut für Stoffwechselforschung, Neuss, Germany and ProSciento, San Diego, US.

\section{References}

1. Miller, K.M.; Beck, R.W.; Bergenstal, R.M.; Goland, R.S.; Haller, M.J.; McGill, J.B.; Rodriguez, H.; Simmons, J.H.; Hirsch, I.B. Evidence of a Strong Association Between Frequency of Self-Monitoring of Blood Glucose and Hemoglobin A1c Levels in T1D Exchange Clinic Registry Participants. Diabetes Care 2013, 36, 2009-2014. [CrossRef] [PubMed]

2. Jenkins, D.J.; Wolever, T.M.; Taylor, R.H.; Barker, H.; Fielden, H.; Baldwin, J.M.; Bowling, A.C.; Newman, H.C.; Jenkins, A.L.; Goff, D.V. Glycemic index of foods: A physiological basis for carbohydrate exchange. Am. J. Clin. Nutr. 1981, 34, 362-366. [CrossRef] [PubMed]

3. Venn, B.J.; Green, T.J. Glycemic index and glycemic load: Measurement issues and their effect on diet-disease relationships. Eur. J. Clin. Nutr. 2007, 61, S122-S131. [CrossRef] [PubMed]

4. Aziz, A.; Dumais, L.; Barber, J. Health Canada's evaluation of the use of glycemic index claims on food labels. Am. J. Clin. Nutr. 2013, 98, 269-274. [CrossRef] [PubMed]

5. Bansal, N. Prediabetes diagnosis and treatment: A review. World J. Diabetes 2015, 6, 296-303. [CrossRef]

6. Zeevi, D.; Korem, T.; Zmora, N.; Israeli, D.; Rothschild, D.; Weinberger, A.; Ben-Yacov, O.; Lador, D.; Avnit-Sagi, T.; Lotan-Pompan, M.; et al. Personalized Nutrition by Prediction of Glycemic Responses. Cell 2015, 163, 1079-1094. [CrossRef]

7. Haak, T.; Hanaire, H.; Ajjan, R.; Hermanns, N.; Riveline, J.P.; Rayman, G. Flash Glucose-Sensing Technology as a Replacement for Blood Glucose Monitoring for the Management of Insulin-Treated Type 2 Diabetes: A Multicenter, Open-Label Randomized Controlled Trial. Diabetes Ther. 2017, 8, 55-73. [CrossRef]

8. Aberer, F.; Hajnsek, M.; Rumpler, M.; Zenz, S.; Baumann, P.M.; Elsayed, H.; Puffing, A.; Treiber, G.; Pieber, T.R.; Sourij, H.; et al. Evaluation of subcutaneous glucose monitoring systems under routine environmental conditions in patients with type 1 diabetes. Diabetes Obes. Metab. 2017, 19, 1051-1055. [CrossRef]

9. Sato, T.; Oshima, H.; Nakata, K.; Kimura, Y.; Yano, T.; Furuhashi, M. Accuracy of flash glucose monitoring in insulin-treated patients with type 2 diabetes. J. Diabetes Investig. 2019, 10, 846-850. [CrossRef]

10. Bailey, T.; Bode, B.W.; Christiansen, M.P.; Klaff, L.J.; Alva, S. The Performance and Usability of a Factory-Calibrated Flash Glucose Monitoring System. Diabetes Technol. Ther. 2015, 17, 787-794. [CrossRef]

11. Kempf, K.; Altpeter, B.; Berger, J.; Reuss, O.; Fuchs, M.; Schneider, M.; Gartner, B.; Niedermeier, K.; Martin, S. Efficacy of the Telemedical Lifestyle intervention Program TeLiPro in Advanced Stages of Type 2 Diabetes: A Randomized Controlled Trial. Diabetes Care 2017, 40, 863-871. [CrossRef] [PubMed]

12. Lippi, G.; Avanzini, P.; Cervellin, G. Prevention of hemolysis in blood samples collected from intravenous catheters. Clin. Biochem. 2013, 46, 561-564. [CrossRef] [PubMed]

13. Matthan, N.R.; Ausman, L.M.; Meng, H.; Tighiouart, H.; Lichtenstein, A.H. Estimating the reliability of glycemic index values and potential sources of methodological and biological variability. Am. J. Clin. Nutr. 2016, 104, 1004-1013. [CrossRef] [PubMed]

14. Patton, S.R.; Clements, M.A. Continuous Glucose Monitoring Versus Self-monitoring of Blood Glucose in Children with Type 1 Diabetes-Are there Pros and Cons for Both? US Endocrinol. 2012, 8, 27-29. [CrossRef] [PubMed] 
15. Erbach, M.; Freckmann, G.; Hinzmann, R.; Kulzer, B.; Ziegler, R.; Heinemann, L.; Schnell, O. Interferences and Limitations in Blood Glucose Self-Testing: An Overview of the Current Knowledge. J. Diabetes Sci. Technol. 2016, 10, 1161-1168. [CrossRef] [PubMed]

16. Hassanein, M.; Abdelgadir, E.; Bashier, A.; Rashid, F.; Saeed, M.A.; Khalifa, A.; Eltayb, F.; Abuelkheir, S.; Abdellatif, M.; Sayyah, F.; et al. The role of optimum diabetes care in form of Ramadan focused diabetes education, flash glucose monitoring system and pre-Ramadan dose adjustments in the safety of Ramadan fasting in high risk patients with diabetes. Diabetes Res. Clin. Pract. 2019, 150, 288-295. [CrossRef]

17. Bolinder, J.; Antuna, R.; Geelhoed-Duijvestijn, P.; Kroger, J.; Weitgasser, R. Novel glucose-sensing technology and hypoglycaemia in type 1 diabetes: A multicentre, non-masked, randomised controlled trial. Lancet 2016, 388, 2254-2263. [CrossRef]

18. Basu, R.; Dalla Man, C.; Campioni, M.; Basu, A.; Klee, G.; Toffolo, G.; Cobelli, C.; Rizza, R.A. Effects of age and sex on postprandial glucose metabolism: Differences in glucose turnover, insulin secretion, insulin action, and hepatic insulin extraction. Diabetes 2006, 55, 2001-2014. [CrossRef]

19. Carpenter, D.; Dhar, S.; Mitchell, L.M.; Fu, B.; Tyson, J.; Shwan, N.A.; Yang, F.; Thomas, M.G.; Armour, J.A. Obesity, starch digestion and amylase: Association between copy number variants at human salivary (AMY1) and pancreatic (AMY2) amylase genes. Hum. Mol. Genet. 2015, 24, 3472-3480. [CrossRef]

20. Dunstan, D.W.; Kingwell, B.A.; Larsen, R.; Healy, G.N.; Cerin, E.; Hamilton, M.T.; Shaw, J.E.; Bertovic, D.A.; Zimmet, P.Z.; Salmon, J.; et al. Breaking up prolonged sitting reduces postprandial glucose and insulin responses. Diabetes Care 2012, 35, 976-983. [CrossRef]

21. Gibbs, E.M.; Stock, J.L.; McCoid, S.C.; Stukenbrok, H.A.; Pessin, J.E.; Stevenson, R.W.; Milici, A.J.; McNeish, J.D. Glycemic improvement in diabetic $\mathrm{db} / \mathrm{db}$ mice by overexpression of the human insulin-regulatable glucose transporter (GLUT4). J. Clin. Investig. 1995, 95, 1512-1518. [CrossRef] [PubMed]

22. Blaak, E. Sex differences in the control of glucose homeostasis. Curr. Opin. Clin. Nutr. Metab. Care 2008, 11, 500-504. [CrossRef] [PubMed]

(C) 2019 by the authors. Licensee MDPI, Basel, Switzerland. This article is an open access article distributed under the terms and conditions of the Creative Commons Attribution (CC BY) license (http://creativecommons.org/licenses/by/4.0/). 